\title{
The Development of Creative Tourism Activities in Ubon Ratchathani Province, Thailand
}

\author{
Suwaphat Sregongsang ${ }^{1}$ and Khemchira Nongped ${ }^{2}$ \\ ${ }^{1}$ Tourim Innovation Program, The Faculty of Liberal Arts, Ubon Ratchathani University \\ Email: Ajarntaes@gmail.com \\ ${ }^{2}$ Tourism Program, The Faculty of Liberal Arts, Ubon Ratchathani University \\ Email: Khemira26@gmail.com
}

\begin{abstract}
This research aims to investigate (1) the cultural resources that promote tourism in Ubon Rachathani province and (2) create the creative activities related to the cultural identities of local people in Ubon Ratchathani province. This researcher conducted this research as a qualitative research and collected data by interview Thai tourists and local people in the local communities. The results of the research was analyzed by descriptive analysis.

The results of the research found that the cultural resources that promote tourism in Ubon Rachathani province comprised of (1) brassware production in Pa-ao community (2) local gong production in Sai Mun community, (3) Ubon Ratchathani Candle Festival and (4) Kab Bua Silk production in Nonsawang community. Therefore, to create the creative tourism activities in Ubon Ratchathani province related to the cultural identities of local people could be designed as the activities that could support the participation of the tourists to join and learn about the cultural identities in the attractions such as the community where local people produced the community products (local gong in Sai Mun community, Kab Bau silk produced in Ban Nonsawang community, to sculpt the candle in the candle festival, and brassware production in Pa-ao community). Moreover, these activities could increase the relationships between the hosts and the visitors, increases social and relational capital for both tourists and local people using existing resources in order to strengthen identity and distinctiveness with the education a self-realization and education.
\end{abstract}

Keywords: creative tourism activities, creative tourism, cultural resources

\section{Introduction}

Creative tourism was the tourism which offered the visitors the opportunity to develop their creative potential through active participation in courses and learning experiences, which were characteristic of the holiday destination where they were taken (Crispin Raymond and Greg Richards, 2000). Creative tourism was also defined as a projection of a new tourism in which natural, cultural and personal resources that were not manipulated and exploited but valued and enriched (Jelincic and Zuvela, 2012. Online). In Thailand, the creative tourism also included the development of a model for creative tourism by identifying activities with high potential and possibility to sustainably develop communities through means of Creative Tourism (Wisudthiluck, 2012).

Therefore, the creative tourism have been considering as a new generation of tourism by involving the tourists themselves and the locals in the creation of the tourist products. Moreover, the growing demand for creative tourism aroused the interest of the destination managers and local governments, seduced by the opportunity to attract a high value tourism by simply fostering their intangible heritage (workshops) and optimizing the use of existing infrastructures (venues rental). In Ubon Ratchathani province, there were many authentic cultural resources to promote as the tourism resources such as local silks, brassware handicrafts, and local gong produced by local communities. However, there was not the development for creative tourism activities based on these existing cultural resources. Thus there should be the design of creative tourism activities in Ubon Ratchathani province in order to increase the tourists' experiences with the local culture by participating in artistic and creative activities and use to combine many types of tourism, during the same journey: creative, culinary, eco-tourism, slow tourism. 


\section{Objectives}

1. To investigate the cultural resources that promote tourism in Ubon Rachathani province

2. To create the creative activities related to the cultural identities of local people in Ubon Ratchathani province

\section{Research methodology}

The researcher conducted this research with qualitative research. For the qualitative research, the researcher used in-depth interview with local government, tourists, tourism scholars, and local community in order to find out the cultural resources that were suitable to promote the creative tourism activities in Ubon Ratchathani province. The results from the qualitative research instrument were analyzed with the concepts of creative tourism.

The researcher conducted the research focusing on three communities in Ubon Ratchathani province, Thailand where the tourists could experience the cultural identities through the local handicrafts such as Pa-ao community, Sai Mun community, and Nonsawang community. Besides the local handicrafts, the researcher focused the research on the candle festival that was the provincial festival of the people here and Tourism Authority of Thailand (TAT) have been promoting this festival as the national festival for tourism in Thailand every year.

\section{Results of the research}

\subsection{The cultural resources that promote tourism in Ubon Ratchathani province}

There are many cultural resources that could be promoted tourism in Ubon Ratchathani province. These cultural resources are also able to present the cultural identity of the local people and attract more tourists to visit here every year. There are following resources;

\subsection{Baan Sai Mun's Gong (Gong in Sai Mun community)}

Gong is a type of Thai musical percussion instrument. There are many types and sizes of gong. Some types are used for signaling such as small gong - to signal the shift change, victory gong - to use as attack signaling for ancient army, etc. Some local people call "Mong", a gong made of sheet metal with a bump in the center circle. It is used to produce the sound by hitting on "Gong Button". From the base unfolds, it hooked down by the so-called "tiered". The ground section is surrounding by the so-called "post-tiered" or "patio umbrella". The bent rim is called "the umbrella". There are holes for string or leather to hang the gongs, use two drilled holes to hang vertically and four holes for horizontal hanging. Gong is used in conjunction with various rites; in which offering gong to temple is the most popular purpose because it is believed to bring fame to the giver. Currently, source of gong production is at Baan Sai Mun, Tambon Sai Mun, Amphur Phibun Mangsahan, Ubon Ratchathani. There are many different sizes of gongs and it is regarded as district's OTOP product, the cultural output and household craft that can plentifully generate income to the community.

Gong is made of variety of materials such as nipa palm, brass, steel, stainless steel, and so on. Different materials cause the melodious sound produced differently. The soft, resonant voice is produced by brass gong which is more expensive than those made of steel, stainless steel. Additionally, the price is based upon size of gongs made of each material. 


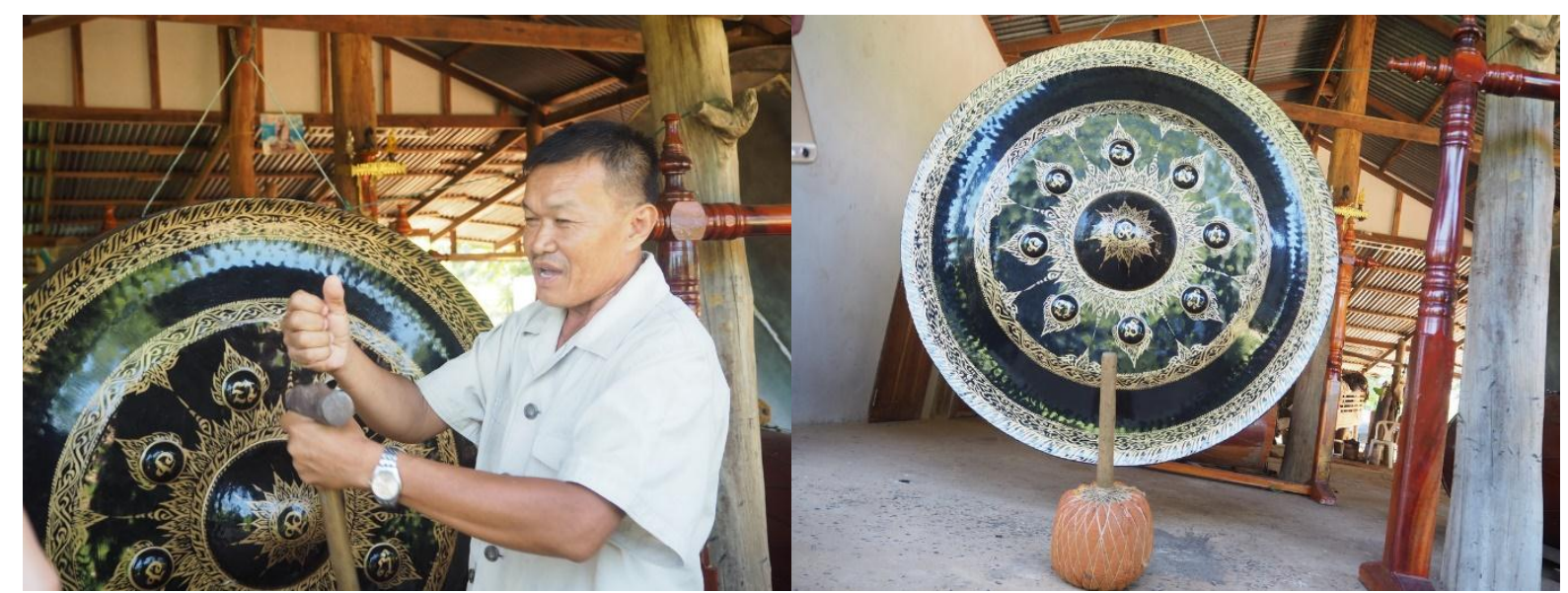

Fig. 1-2: The local interpreter explained about the important roles of the gong (left) and the design decoration of local gong (right)

The length of gong measured by a palm span or by a fist is believed among Northeastern people that it implies the following meaning; $1^{\text {st }}$ success and fortune, $2^{\text {nd }}$ hit the gong without lone, $3^{\text {rd }}$ sound produced is loud and wide, $4^{\text {th }}$ sound produced is loud around the earth, $5^{\text {th }}$ watched by numerous consort queens, 6 th to be the king of brass plate, $7^{\text {th }}$ to position for city governor parade, $8^{\text {th }}$ to rally the warriors, $9^{\text {th }}$ to remove the phantom, 10th to frighten Mother Earth, and 11th to hit at the marquee for victory.

\subsection{Ban Pa-ao's brassware (Brassware in Pa Ao community)}

At Ban Pa-ao, Tambon Pa-ao, to the west of Ubon Ratchathani town, there is a story. The people of Ban Paao are believed to have originated from Vientiane and migrated down to Nongbua Lamphu. The reason for this theory is that an archaeological discovery was made in Nongbua Lamphu. Tombs were found with skeletons and small bells thought to be from bracelets or anklets. Later, some bells with an identical pattern were found at the Ban Chiang archaeological site in Udon Thani and Ban Khor in Maha Sarakham. The trails of these brass bells did not stop there but continued along the road down south to Ban Pa-ao.

$\mathrm{Pa}$-ao. Here, they have been making ancient bells like these since the time of them ancestors. In this area, they are famous for them craft of cast brass. This is an account from the legendary brass artisan of Ban Pa-ao, Mr. Boonmee Lomwong, a sixth-generation brass artisans who has inherited his craft from his late father, Thong Lomwong.
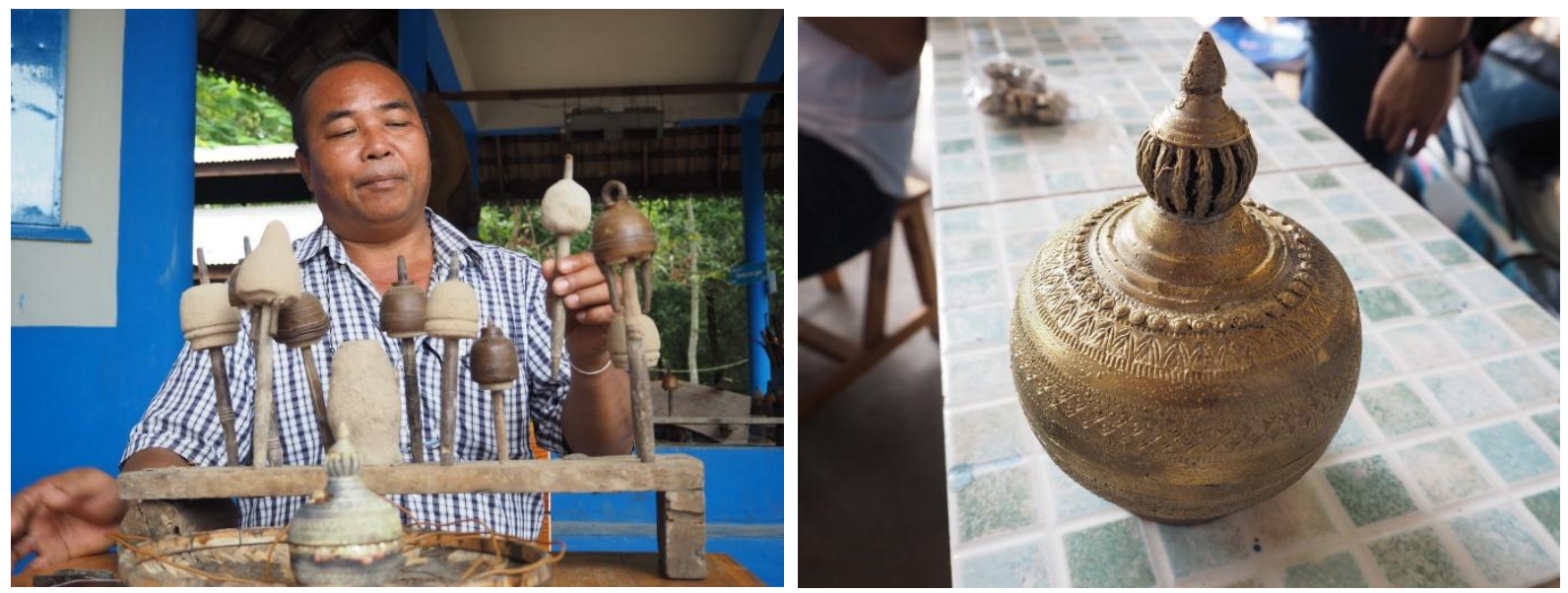

Fig. 3-4: The local artisan in Pa-ao community presented the process of the brassware production (left) and the sample of the brass ware product (right)

This is an account from the legendary brass artisan of Ban Pa-ao, the beautiful patterns that appear on the gold-coloured metal surface of bells, betel leaf pockets, utility caskets, water dippers, betel mortars and many more recall a prosperous civilisation and lifestyle. Ban $\mathrm{Pa}-\mathrm{ao}$ is the only place in Thailand where this ancient technique is still practiced typical brassware is always made using the "wax substitution", Mr. Boonmee says. 
Ban Pa-ao seems a relatively quiet community without any special public relations to boast of but a few do know that its brassware has been showcased in several blockbuster movies. Betel receptacles and brass kettles have been used on the sets of "The Legend of Suriyothai" and "The Legend of King Naresuan the Great".

\subsection{Ubon Ratchathani Candle Festival}

The Thai word phansa refers to a period of three months in the rainy season during which time Buddhist monks are obliged to stay at one particular temple. They are not allowed to stay overnight at other temples during this time. The reason that monks have to stay at one temple is because this period of time is the riceplanting season and the farmers' crops are a verdant green. If monks are out travelling during this period, they may inadvertently step on the rice sprouts that have been planted, resulting in the loss of crops. The Lord Buddha therefore ordained that monks should stop their pilgrimages for a period of three months during the rainy season and that they must not stay overnight in a place other than their chosen temple. (Khao phansa means 'rain retreat' or 'Buddhist Lent') Khao phansa has taken place since the time of the Lord Buddha.

Khao Phansa Day is the first day of the waning moon of the eighth month of the lunar calendar, or during the month of July and extends for a period of three months until Ork Phansa Day which is the end of the period of time. Ork Phansa Day falls on the fifteenth day of the waxing moon of the eleventh month of the lunar calendar, or during the month of October. (Note: The Thai calendar originally began in our month of December. Therefore, the eighth month is July and the eleventh month is October.) When monks stop their travels during the Buddhist Lent period, they have time to study, and they especially like to read. The best time for reading and memorising is during the night, which is a peaceful, quiet time during which it is easy to concentrate. In the past, when there was no electricity, monks used to light candles during the time that they were reading. When villagers knew this, they made candles to present to the monks, especially for presentation on Khao Phansa Day, a day on which they would receive even more merit than usual. Merit in this case means that the lives of those who present candles will be happy, healthy, enlightened and not gloomy. In other words, they will be people with wisdom, knowledge and perception, which is equivalent to the English word 'bright'. The presentation of candles to monks on Khao Phansa Day is a Buddhist tradition which began in ancient times and still continues at present. However, present-day villagers tend to present electric light bulbs or fluorescent tubes as they are brighter than candles, are easier to use, and more convenient, and they still receive the same amount of merit. (Peter Gadd. 2016. Online)

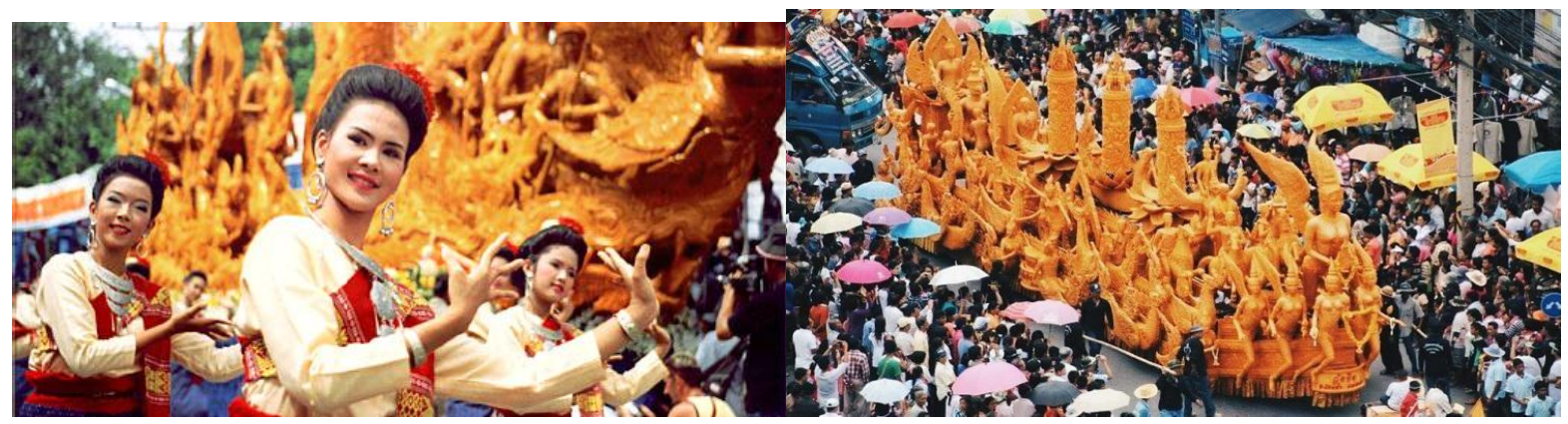

Fig. 5-6: Traditional dance in the candle festival (left) and the candle parade along the road in Ubon Ratchathani province (right)

The people of Ubon Ratchathani are the same as other Buddhists - when Khao Phansa Day arrives, they take candles and present them to monks. In the past, when it was impossible to buy ready-made candles, villagers would use beeswax taken from bees' nests. They would melt the beeswax and then immerse a length of cotton to be used as a wick into the molten beeswax. Next, the wax would be left until it was cool enough to be rolled by hand, surrounding the wick completely.

Presenting candles to monks in the past did not include a parade and candle contest like we have at present. It was just a presentation of candles along with other offerings to monks and receiving blessings from the monks, followed by the journey home. The reason that there must be a parade and a contest like we have today came about during the reign of Rama V, when the King's grandson, Prince Sappasittiprasong, was made governor and came to rule over the Lao Kao circle, which was established in the town of Ubon Ratchathani. He saw the injuries and deaths that the villagers suffered during the traditional rocket festival. The injuries and deaths were due to rockets that exploded and fell onto houses; other injuries and deaths were due to arguments and fights due to drinking excessive alcohol; sometimes it was due to playing with excessive energy in the mud; 
or, amusement with wooden dolls produced to look like they were making love. The Prince decided that these stories were bad, inappropriate, and ordered the rocket festival to stop, and for a candle festival with candles being presented to monks to take its place.

The production and procession of candles in Ubon Ratchathani has taken place for hundreds of years. Thus, a lot of development has taken place too, as previously described. From the simple candle parade in the beginning, to today's dancing-, music- and acting-enhanced pageant. From the combination of the hands and energy of small groups of villagers in various communities in an economical way, to working with various groups of villagers, traders and civil servants in a more expensive way. From manual labour and transport on a cart, to transport on a motorized vehicle. From a small vehicle, to a large vehicle. From a large vehicle, to many vehicles. From a short vehicle, to a long vehicle. From prizes worth just a few baht, to prizes worth hundreds of thousands of baht. From administration solely by Ubon Ratchathani province, to administration in cooperation with the Tourist Authority of Thailand. From having no tourists, to having both Thai and foreign tourists. All of these various types of development have made the candles so different, so beautiful and so magnificent.

\subsection{Ban Nonsawang's Kab Bua Silk}

Silk made from local materials base on the lotus plants Ban Nonsawang, Ubon Ratchathani Province.Ubon Ratchatani is known as the Lotus City. The plant is the inspiration for the Kab Bau silk produced in Ban Nonsawang, a village in a province of Ubon. The silk is characterized by its beautiful design.

Ubon Ratchathani, bordering Laos to the east and Cambodia to the south, is a province with a long and interesting history. The area is famous for the beautiful flowers of its lotus plants. Silk has been a product of the villages for many years as a fabric for clothing, gifts, and the safe storage of ancient palm leaf scriptures, and the skills involved in its lure have been practiced and passed down over the ages. Much of the silk has a close association with the legends, shapes, and colors of the lotus plant.

The most famous Kab Bua silk of Ubon Ratchathani is from Ban Nonsawang in Kut Khaopun district. The skills, techniques, and wisdom of weaving have been practiced here for 200 years. The Kab Bua silk produced in Ban Nonsawang is of a high quality has been recognized by the award of 'Outstanding Product' of Ubon Ratchathani in 2002 and the OTOP 5-Star Awards in 2004 and 2006.
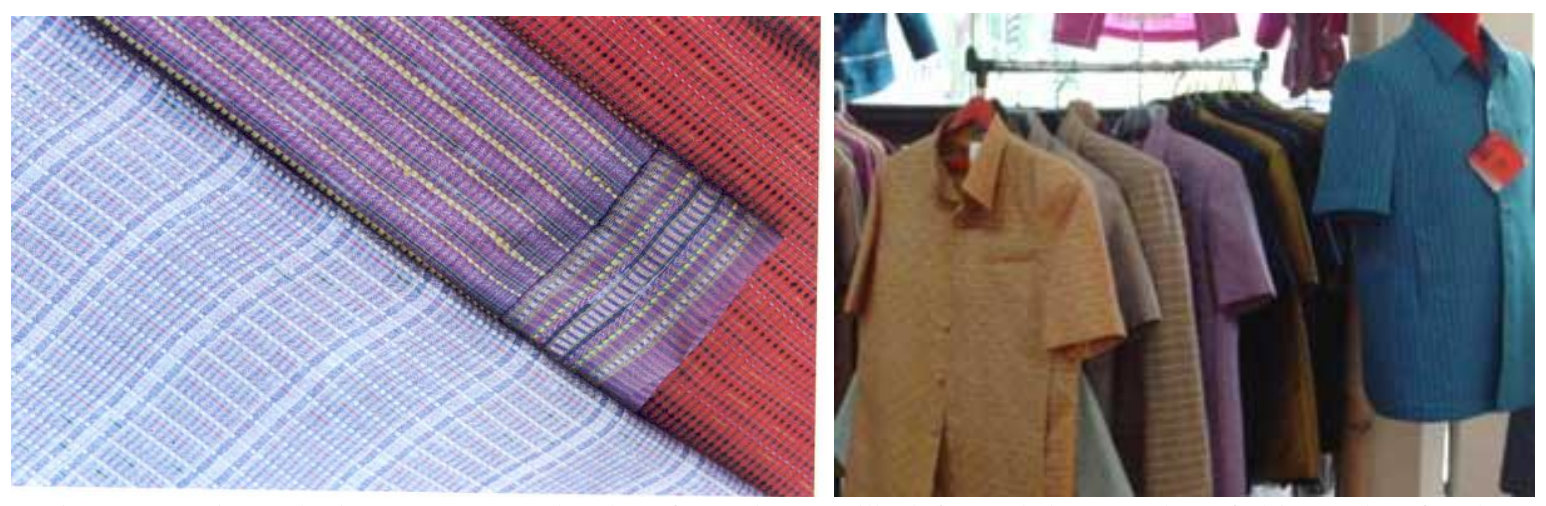

Fig. 7-8: Various design patterns and colors for Kab Bua silk (left) and the samples of shirt made of Kab Bua silk (right)

\subsection{The Tourist's Demands toward Creative Ecotourism Activities in Ubon Ratchathani province}

According to the results from interviewed the tourists who visited Ubon Ratchathani province, the tourists suggested the creative tourism activities based on the cultural resources in Ubon Ratchathani province as follows;

4.6.1. The creative tourism activities should be designed as the activities that could support the participation of the tourists to join and learn about the cultural identities in the attractions such as the community where local people produced the community products (local gong in Sai Mun community, Kab Bau silk produced in Ban Nonsawang community, to sculpt the candle in the candle festival, and brassware production in $\mathrm{Pa}-\mathrm{ao}$ community). (Sudarat Amornmanee. 2016. Interviewed)

4.6.2. There were many kinds of souvenir to serve the tourists such as the shirt painted with the pictures of the candle festival, silk products, gong, and brassware etc. Moreover, there should be the activities for the 
tourists to learn and join the production process of the souvenirs as the creative tourism. (Amornrat Sirikan. 2016. Interviewed)

4.6.3. The Creative tourism activities should increase the relationships between the hosts and the visitors, increases social and relational capital for both tourists and local people using existing resources in order to strengthen identity and distinctiveness with the education a self-realization and education. (Kanchana Manithong. 2016. Interviewed)

\subsection{Creative Activities Related to the Cultural Identities of Local People in Ubon Ratchathani Province \\ According to the toruists' demands and the cultural identities of communities in Ubon Ratchathani province, the sample of the creative activities in Ubon Ratchathani province could be designed as following activities;}

4.7.1. Visited communities and saw candle making, visited of communities and temples could be made to see the making of festival candles about 2-3 days prior to the procession. Visitors could learn about the techniques and methods used, as well as the designs applied to the candles.

4.7.2. Candle procession on Asanlaha Bucha Day at Ubon Ratchathani temples, a candle procession circling the convocation hall on Asanlaha Bucha Day would be held in the evening at various temples. Not only would visitors have the chance to see this important Buddhism ceremony, but they could also delight in exquisite local architecture of the temples.

4.7.3. Displaved of candles around Thung Si Muang and the grandest candle exhibition in Thailand, the candles would be fully decorated and the site where the candles were placed would be illuminated with highpowered lighting and cleaned up. Thus, an ideal setting for the candles was created, making the display the most beautiful and most complete candle exhibition in Thailand.

4.7.4. The candle parade, it was on the Buddhist Lent Day from 08.00 hours onwards. The parade would pass the provincial hall along Upparat Road and Chayankun Road for a distance of 2-3 kilometers before disbanding. It would consist of a royal candle parade and candle parades form temples, each with accompanying local performances, dances and music.

4.7.5. Merit-making to donate candles, this was considered the heart of the Buddhist Lent. Buddhists would take candles and items for the personal use of monks to donate to monks at nearby temples. This was regarded as a great blessing to the donor. Visitors could participate in this beautiful ritual at all temples.

\section{Discussion and Conclusion}

The creative tourism was a new form of tourism that gave the importance to the engagement of tourists and hosts by providing opportunities for tourists to participate in various activities and learn from authentic, handson experience in the local community. This allowed the tourists to learn and gain a deep understanding of the cultural heritage in various communities. In addition, the creative tourism did not only create relaxation or excitement, but also personal pride, a bond with hosts and memorable experiences from the place of visit.

The researcher used the concept of creative tourism from Greg Richards (2010) to analyze and present the creative tourism activities in Ubon Ratchathani province. He defined the concept of creative tourism as tourism which offer visitors the opportunity to develop their creative potential through active participation in courses and learning experiences which are characteristic of the holiday destination where they are undertaken. According to that definition of the creative tourism, the research had presented the creative tourism activities for candle festival as the main sample for creative tourism activity in Ubon Ratchathani province. This activity could support the tourist to participate, learn, and increase their experience about the important roles of the candle festival as the cultural resource to the local people in Ubon Ratchathani province. 


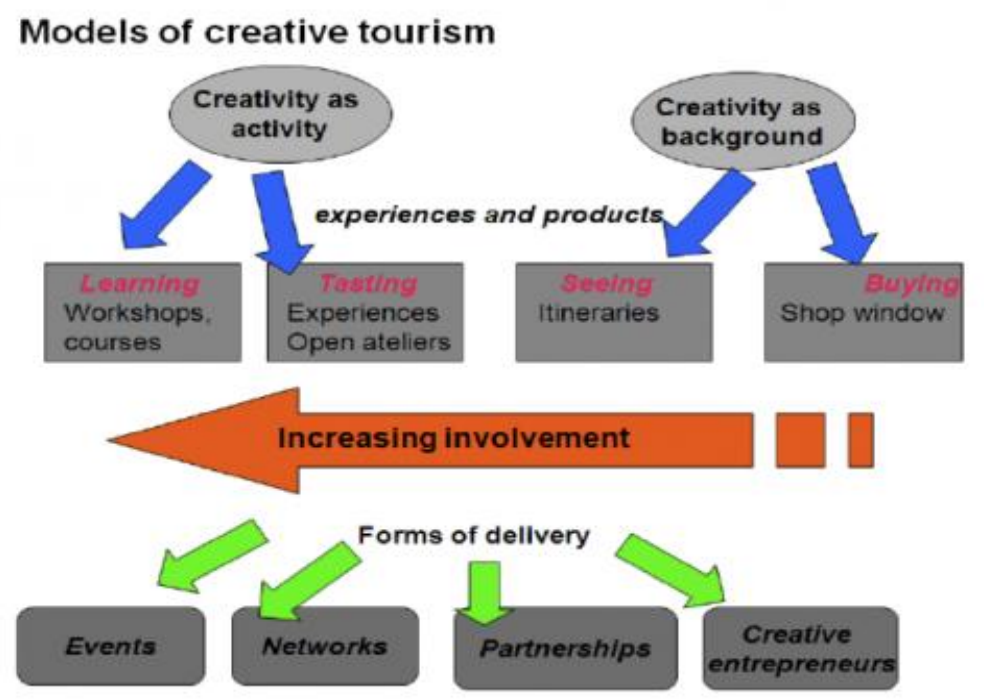

Fig. 1: Creative tourism model Source: Elena Paschinger. 2016. (Online)

According to the creative tourism model in figure1, it could emphasize that the creative tourism activity designed for the candle festival in Ubon Ratchathani such as to join the candle procession on Asanlaha Bucha Day at Ubon Ratchathani temples, display of candles around Thung Si Muang and the grandest candle exhibition in Thailand, the candle parade, and merit-making to donate candles. These learning activity could increase the tourists' experiences towards the importance of the candle. Besides the learning activity, the testing activity was also important for the tourists increasing their experiences for practice their skill to sculpt the candle with local candle tracery and the candle production processes.

\section{References}

[1] Amornrat Sirikan. 2016. The tourist who visited Nonsawang community. [nterviewed: 17 August, 2016].

[2] Elena Paschinger. (2016). Re-humanizing the relationship between visitors and locals. Retrieved June, 2016 from. http://blog.kreativreisen.at/creative-travel-posts-in-english/re-humanizing-the-relationship-between-visitors-and-locals

[3] Jelincic and Zuvela, 2012. About the Creative Tourism. Retrieved June, 2016 from. http://www.creativetourismnetwork.org/about

[4] Kanchana Manithong. 2016. The tourist who visited Sai Mun community. [Interviewed: 21 August, 2016].

[5] Peter Gadd. (2016). Candle festival in Ubon Ratchathani. Retrieved June, 2016 from. http://www.ubonguide.org/book14/formcover14_1e.html

[6] Richards, G. (2010). Creative Tourism and Local development. Creative Tourism: A Global Conversation: How to Provide Unique Creative Experiences for Travellers Worldwide. Santa Fe, USA. UNESCO. (2004). Universal Declaration on Cultural Diversity. Retrieved June, 2016 from. http://unesdoc.unesco.org/images/001 2/001271/127160m.pdf

[7] Richards, G. and Raymond, C. (2000) Creative tourism. ATLAS News no.23. Tilburg University.

[8] Sudarat Amornmanee. 2016. The tourist who visited Pa-ao community. [Interviewed: 15 August, 2016].

[9] Wisudthiluck, S., et al. (2000). Creative Tourism Model. Retrieved June, 2016 from. http://www.dasta.or.th/creativetourism/th/projectativies/117-117.html

[10] Wurzburger, R. (2010). Introduction to the Santa Fe \& UNESCO International Conference a Global Conversation on Best Practices and New Opportunities. Creative Tourism: A Global Conversation: How to Provide Unique Creative Experiences for Travellers Worldwide. Santa Fe, USA. 